\title{
A qualitative study of women's use of emergency contraception
}

\author{
Louise A Keogh
}

\begin{abstract}
Background While the use of emergency contraception $(E C)$ is becoming more widespread in Australia, little is known about the reasons for, and the social context of, this use.

Methods In order to explore the use of EC from the perspective of users, a qualitative study was conducted with women presenting to one of three health care settings in Melbourne, Australia for EC.
\end{abstract}

Results Thirty-two women ranging in age from 18 to 45 years were interviewed. While a number of themes were discussed with the women, this paper reports on four 'types of users' of EC identified from the data. 'Controllers' experienced failure of their contraceptive method and were very uncomfortable needing EC. They changed their contraceptive strategy in an attempt to avoid needing EC in the future. 'Thwarted controllers' were similar to controllers except that they could not improve their contraceptive strategy due to medical or social limitations. 'Risk takers' saw the use of EC as a component of their overall contraceptive strategy. They did not rely on EC regularly, but were comfortable to use it occasionally when the need arose. A final group of women were caught short' by a sexual experience that was unplanned and therefore they did not manage to use their chosen contraceptive strategy.

Conclusions The findings from this study challenge the assumptions that are often made about the users of EC and highlight the need to acknowledge the different ways that women make sense of, and make decisions about, contraception.

\section{J Fam Plann Reprod Health Care 2005; 31(4): 288-293} (Accepted 28 April 2005)

\section{Key message points}

- Four 'types of users' of emergency contraception (EC) have been identified: 'controllers', 'thwarted controllers', 'risk takers' and 'caught short'.

- Different types of users will have different needs at the time of accessing EC.

- It is time to acknowledge the legitimacy of women's ways of making sense of, and decisions about, contraception.

Key Centre for Women's Health in Society, Department of Public Health, University of Melbourne, Melbourne, Australia Louise A Keogh, MA, PhD, Research Fellow

Correspondence to: Dr Louise A Keogh, Key Centre for Women's Health in Society, Department of Public Health, University of Melbourne, Melbourne, Victoria 3010, Australia. Tel: +613 8344 4333. Fax: +61 393479824

E-mail: I.keogh@unimelb.edu.au

\section{Introduction}

"In the last decade of the 20th century, emergency contraception (EC) emerged from being the 'best-kept secret' in contraception to become "one of the hottest topics in reproductive health." in over 80 countries worldwide. ${ }^{2}$ Awareness of EC ranges from around $50 \%$ in the USA to over $90 \%$ in the UK according to Ellertson et al. ${ }^{3}$ and is higher among younger women than older women. There is also large variation in the proportion of women who have used EC, ranging from $1 \%$ of men and women over the age of 18 years in the $\mathrm{USA}^{4}$ to $12 \%$ of $16-49$-year-old women in the $\mathrm{UK}^{5}$ and $19 \%$ of $16-59$-year-old Australian women. 6

There is evidence that EC is becoming a valuable technology in the contraceptive repertoire available to women in the 21st century in some developed countries. In the last 30 years, condom use has been promoted in the context of disease prevention and has become a preferred contraceptive for a significant number of women, especially young women. [NB. Some $53 \%$ of $16-19$-yearold women exposed to the risk of pregnancy in a representative sample of Australian women were using condoms. ${ }^{7}$ ] Given the failure rates associated with contraceptives in general, and with condoms in particular, $\mathrm{EC}$ is an important backup for women following exposure to a pregnancy risk. A recently published Australian survey reported that $19 \%$ of 16-59 year-old women and $40 \%$ of 20-29-year-old women 6 had used EC. These figures imply that it is critical to understand EC use if we are to provide appropriate and adequate services for users.

Conversely, Ellertson et al. suggest that: "emergency contraception seems to be singled out for special scrutiny and mistrust among other public health 'back-up' options (e.g. having a fire extinguisher in the home, wearing a seatbelt in the car) to the point that some providers are reluctant to pass the message along at all". 3 So the fact that $\mathrm{EC}$ acts after intercourse, rather than before, continues to affect its acceptance as a strategy for preventing pregnancy in many settings.

Published quantitative research has addressed the uptake of EC by assuming that with increased knowledge and a positive attitude, appropriate use of EC will increase. Studies have reported significant misperceptions about EC both amongst users ${ }^{8}$ and providers. 9 Boonstra 10 summarises the major misperceptions as follows: "that emergency contraception is something new and untested or inherently unsafe, and that it is comparable to an abortion". The assumption in most research is that these misperceptions could present a significant barrier to the uptake of EC. However, studies of women undergoing termination of pregnancy often reveal high levels of knowledge of EC,11,12 suggesting that other factors may play a more significant role in women's decision to use EC.

The literature that deals with users of EC shows that the most common reason for women needing EC is condom failure, followed by missed oral contraceptive pills and no contraceptive or withdrawal. ${ }^{13-17}$ The present study was designed to examine the situation that led to needing EC, the decision and experience of using it and the consequences for contraceptive use, in order to enhance our understanding of, and our capacity to, optimise the use of this technology. 
Table 1 Demographic characteristics of the sample

\begin{tabular}{lc}
\hline Demographic characteristic & Women $(n)$ \\
\hline Age group (years) & 7 \\
$18-20$ & 8 \\
$21-25$ & 11 \\
$26-30$ & 3 \\
$31-35$ & 0 \\
$36-40$ & 3 \\
$40+$ & 24 \\
Country of birth & 8 \\
Australia & 26 \\
Overseas & 6 \\
Relationship status & \\
Ongoinga & 1 \\
Casual & 13 \\
Current position & 3 \\
Full-time management & 1 \\
Full-time professional & 10 \\
Full-time in service industry & 3 \\
Full-time blue collar worker & 1 \\
Full-time university student & 32 \\
Part-time university student & \\
Unemployed & \\
Total &
\end{tabular}

ancluded relationships ranging in length from 6 weeks to 5 years in addition to de facto relationships and marriages.

\section{Methods}

Users of EC were recruited through three sites in metropolitan Melbourne, Australia: a family planning clinic, a sexual health centre and a hospital emergency department. Data were collected prior to EC receiving marketing approval (this occurred in July 2002). At the time of data collection, EC was provided 'off-label', meaning that oral contraceptive pills were prescribed for a purpose other than that for which they had been approved. Sites offered both the Yuzpe method and the progestogen-only method. At each site, providers of EC offered all users a flyer inviting them to join the study and interested participants left their contact details in a secure box in the clinic. Participants were contacted 2 weeks after the date of their consultation and were invited to be interviewed about their experience of using EC. A total of 32 interviews were conducted between August 1999 and October 2000 in a variety of settings (homes, cafés, parks, etc.). The demographic characteristics of the participants are summarised in Table 1 and indicate that this sample fits the profile of users from the literature: young, educated and in a relationship. ${ }^{13}$

Interviews were semi-structured, focusing on several key areas: the situation that led to the need for EC, the experience of using it, and contraceptive decision-making before and after the event. As so little is known about the experience from women's perspective, qualitative methodology was used to allow themes to emerge from the data, rather than being imposed prior to data collection, through the use of a structured questionnaire. I referred to EC as 'the morning after pill' in interviews as this was the term most familiar to women, and the term they seemed to favour.

Interviews were transcribed verbatim and any identifying information disguised. All transcripts were read until several key themes could be identified by the author. From these themes a coding framework was constructed, comprising different concepts that were consistently raised throughout the interviews. Sections of the interviews were then grouped under the relevant codes and further analysed. ${ }^{18}$ Themes explored included reason for needing $\mathrm{EC}$, decision to use EC, access, information sources, perceptions of $\mathrm{EC}$, previous use or non-use of $\mathrm{EC}$, and a range of themes on contraceptive decision-making including consideration of sexually transmitted infections and plans for future childbearing. Rather than present a summary of each theme covered, it seemed more useful to present an analysis of women's use of EC. Based on my analysis and interpretation of the women's stories, I have defined four 'types of users' of EC. Excerpts from transcripts are used to illustrate each of the different types of users. Other aspects of the analysis will be reported elsewhere.

While women's accounts sometimes indicate a misperception regarding either contraception or the use of EC, I did not specifically analyse these misperceptions for the purpose of this article, as I was more interested in women's decision-making processes than whether the information they relied on was strictly correct. I did, however, answer any questions women had, offered them information and advice at the conclusion of the interview where appropriate, and encouraged them to use the services available in Melbourne where necessary.

I entered this research with a desire to offer the women respect for the knowledge they had and the decisions they made, but also to allow for the possibility of failure and confusion in their fertility management. Most importantly, I wanted to offer them the opportunity to tell the whole story as they recalled it. This political stance has no doubt impacted on the way I approached the interviews, and the way I analysed the interview data.

Ethics approval for this study was obtained from La Trobe University, The Department of Health, Family Planning Victoria and the Royal Women's Hospital.

\section{Results}

Contraceptive data collected from the women (Table 2) reveal behaviour consistent with previously reported findings on users of $\mathrm{EC}$ in that the majority had been relying on condoms. ${ }^{13-17}$ It became clear from the interviews that the use of EC involved much more than a simple failure of contraception. Using EC arose out of a number of interrelated decisions made by women, and had different meanings for women. The four subtly different 'types of users' defined in this research are: 'controllers', 'thwarted controllers', 'risk takers' and 'caught short'. The following categorisation of users of EC reveals differences but also commonalities among this group of women. All were attempting to control their fertility, and all had experienced failure of a form of contraception.

\section{Controllers}

I defined 'controllers' as women who desired a high degree of control over their fertility and were uncomfortable taking a risk that may lead to pregnancy. Women in this

Table 2 Contraceptive characteristics of the sample

\begin{tabular}{lc}
\hline Contraceptive characteristic & Women $(n)$ \\
\hline Contraceptive used at time of needing EC & 17 \\
Condoms & 6 \\
Nothing & 3 \\
Oral contraceptive pill: missed pill & 3 \\
Oral contraceptive pill: antibiotics & 1 \\
Diaphragm & 1 \\
Billings' method & 1 \\
Withdrawal & 13 \\
Previous use of EC & 9 \\
Never & 10 \\
Once & \\
Twice or more & 26 \\
Previous abortion & 6 \\
None & 32 \\
One or more & \\
Total &
\end{tabular}

EC, emergency contraception. 


\section{ARTICLE}

category explained that the use of EC was a sign that their contraceptive strategy was inadequate. These women all responded to the experience by increasing their level of contraception. Five women were relying solely on condoms and had experienced condom failure; two were using the pill and were prescribed antibiotics without being cautioned that the antibiotic may interfere with the efficacy of the pill. Unlike other women interviewed, these women felt action needed to be taken to lower the likelihood of needing EC again. All five women who had been relying on condoms planned to begin using the pill following this incident. The following quote from Rebecca illustrates the need for control and the shift from using only condoms to using condoms and the pill. [NB. In all the quotes that follow, the symbol // denotes that a large part of irrelevant dialogue has been removed.]

Rebecca is a 21 -year-old student and part-time worker who lives at home and has been in a relationship for 3 months.

Rebecca: I've had two experiences of the morning after pill. I'll tell you about the one that broke. Um, I don't know, normally after we have sex, we always take the condom and tie it up to see if it's leaking, and this one was leaking.

Louise: You do that every time?

Rebecca: Yeah, that's our little trick to see whether it leaks or not. ... It's so weird, I have to do it. [demonstrates] We tie it up and we pull it, that's the only way we can tell, and to be really sure. And so we found out it was leaking and I'm like, 'OK, I have to go on the morning after pill'. I/

Rebecca: Yeah. And the second time I had to get the morning after pill was because we thought his penis had gone in, and so we wanted to make sure and get it.

Louise: So you weren't using a condom?

Rebecca: We were using a condom, but we were just foreplaying, and it got to almost penetrationtype thing and we decided maybe we should. /I

Louise: So what made you decide to go on the pill?

Rebecca: Because we were having sex on a regular basis, and slip-ups still occurred and I couldn't just keep running back and forwards to the Centre or the Hospital asking for the morning after pill. Because I don't know, it just stresses my body out so much and I was losing a lot of weight. //

Louise: Are you going to stop using condoms now that you are on the pill?

Rebecca: Um, no, I still want to use the condoms, like if things change later, like if we got married I'd probably stop using condoms, but keep the pill happening.

Rachel and Anna each told a very similar story to Rebecca. They were aged 18 and 20 years, respectively, and when starting their relationships had chosen to use condoms. The experience of needing EC prompted them to adopt the pill as well to further protect themselves from the risk of falling pregnant. Indira and Jo were older (32 and 29 years, respectively) and had used the pill previously but both were relying on condoms in the short term for different reasons. Both quickly found this was inadequate and resumed their use of the pill.

Also included in this group were Isobelle and Grace, both aged 23 years. They had both been prescribed antibiotics by a general practitioner, and remembered the next day that this may interfere with the effectiveness of the pill. Neither had been warned of this by their doctor, and both were unhappy that they had been placed in this position.

\section{Thwarted controllers}

The second group identified was the 'thwarted controllers'. These seven women have been defined as 'thwarted controllers' because they were similar to 'controllers' in that they were uncomfortable needing EC but were thwarted in one way or another in their attempts to avoid needing EC in the future. For five women there were medical reasons that prevented them from adopting a more effective contraception strategy, and for two women work or relationship issues limited their options. Below is an extract from the interview with Nicky who is typical of what I have called a 'thwarted controller'

Nicky is 20 years old, and recently became engaged to her partner of 2 years. She works full time and lives with family.

Nicky: When I was 14 ... I got endometriosis ... So since then, I've been in and out of hospital heaps, and about 8 months ago now, I had a partial hysterectomy done ... What happened was, one of the laparoscopies that I had, I picked up an infection from one of those ... but they didn't pick it for 12 months. So it turned into PID [pelvic inflammatory disease], and my Fallopian tube swelled up so much it was irreparable, and they had to remove it, and one of my ovaries and stuff. But because of that, I have to be careful as far as ectopic pregnancies go.

Louise: Yeah

Nicky: So I've never used the morning after pill before this time, um, and like we also use protection, because it's so dangerous, like ectopic pregnancies and that sort of thing. But um, the condom broke last time when we used it. //

Louise: So how did you know about the morning after pill?

Nicky: Well, health class in high school. Like not putting it down or anything, but I never thought it would be something I would take. It's like, I've always been really, really, responsible as far as contraception is concerned, because of my illness, because I have to be. //

Louise: And so you use condoms?

Nicky: I'm on the pill but I can't always use that because of my cycle. So I'll go on it for a couple of months, and then go off it for a couple of months, because my body relies on it too much otherwise ... But we've always used condoms regardless of whether we were using the pill or not, even when we were on it, so yeah.

Louise: So why do you use condoms anyway?

Nicky: Because of my illness, because it's so dangerous. Like I've read up on ectopic pregnancies, and they can kill you and stuff. That just freaks me out big time, and because I had one of my tubes removed as I said, but the other one was reconstructed, it's not completely clear, so the chances of it getting caught in there is more great.

Nicky expressed a preference for using condoms and the pill but because of her medical condition could only achieve this some of the time. When relying solely on condoms Nicky felt she was placed at an unacceptably high risk of falling pregnant. Similarly, Maria, Teresa and Mandy were all using condoms for contraception because of a medical complication that prevented them from using the pill (cerebral hypertension, depression triggered by the pill, and long-term use of antibiotics). These women would 
have preferred the safety of the pill but felt forced instead to rely on condoms and relied on EC when condoms broke or were not used correctly.

Emily faced the opposite problem as she told me she was 'allergic to condoms'. When the pill was contraindicated by her regular need for antibiotics, she relied on abstinence or EC to protect her rather than being able to use condoms as an alternative.

A further two women in this group were thwarted by medical issues that were complicated by social issues. Selma's partner was unwilling to use condoms and she had previously fallen pregnant on the pill. At the time of the interview she was relying on EC as her sole contraceptive, and was very unhappy with this situation. She was exploring the possibility of having an intrauterine device inserted. Serena found taking the pill every day was difficult due to her hours as a shift worker and relied on EC when she missed pills. So while a high degree of control was desirable amongst this group, they felt external factors prevented them from achieving this state.

\section{Risk takers}

A third group of 13 women saw EC as part of their contraceptive strategy rather than a major disruption to it. I have defined them as 'risk takers' because they were comfortable with the risk inherent in using EC. For them the use of EC was not seen as a sign of an ineffective contraception strategy, but instead as an acceptable part of their overall contraceptive strategy, given the issues they were managing in their contraception. They did not take any specific steps to avoid needing EC again.

Some women were committed to a particular method that resulted in them occasionally needing EC as a back up. Eliza, Melany, Tina and Eve were committed to using condoms, Ruth was committed to using a diaphragm, and Jodie was committed to using the Billings' method. For these women, the fact that their commitment to these methods put them at occasional risk of needing EC was not enough to deter them. An extract from the interview with Eliza illustrates this commitment.

Eliza is a 25-year-old unemployed single woman, recently returned from overseas, and was living with a friend at the time of the interview. Louise: $\quad$... so what contraception had you been using?
Eliza: $\quad$ Condoms, and it broke.

Louise: So you knew about the morning after pill when it happened?

Eliza: Yeah, I'd taken it twice before, um, I think just condom breaking yeah. So in terms of contraception, I was on the pill ... for about a year of my two-year relationship, which was, I didn't like it, it felt like my body wasn't mine, my emotions and my body, my breasts were doing strange things. I don't know, I just wasn't happy with it, more on the emotional side, I didn't feel like I had control of what I was doing. I also heard on Triple J, from Dr Karl, and he was saying how there's a theory about the pill, that it alters your sense of smell, so since the 70 s and the introduction of the pill, there's been a higher rate of divorce, women are being attracted to the wrong men because of the pheromones. [Triple $\mathrm{J}$ is the Australian Broadcasting Commission's youth radio network, and 'Dr Karl' does regular science talkback on the network.]

Louise: Wow, I haven't heard that before.

Eliza: $\quad$ Me neither, things like that, we don't really know what it does to our bodies. //
Eliza:

... Yeah so when we were first having sex, I was on the pill, and we were using two condoms. // Louise: You just really didn't want to get pregnant?

Eliza: We just didn't know, like the thought of just taking this little pill once a day, how does it work? Where does it go? I digest it and it goes out of my body. Like I talked to my mum, I can talk to her, and I remember on the phone or in a letter, 'Is this how it's meant to be?' and she was like, 'No, you don't have to use condoms'. And she was just so cool about it, 'The pill's enough'. But still, I always remember afterwards being scared that I was going to get pregnant ... Not feeling entirely comfortable, which I guess also now, is the same kind of feeling why I wouldn't go on the pill, mini-pill or whatever. I just think if it's in a condom, I can see it, and it hasn't gone inside me.

Despite the fact that using condoms has led to a need for EC on more than one occasion, Eliza shows no desire to increase her level of contraception. Her chosen method provides her with a sense of safety that the pill does not.

Other women in this group had a reasonably effective method but problems arose due to non-compliance. Their level of acceptance of risk ranged from a sense of fatalism about the likelihood of 'stuff-ups', to a reasoned decision to take the risk of needing EC to avoid other risks such as those associated with the pill or Depo-Provera ${ }^{\circledR}$. None of these women showed a desire to change to a 'safer' method. Sandra, Skye and Sophie used condoms inconsistently. Magda and Jane both used the pill but did so inconsistently, and Melissa used a combination of withdrawal and the rhythm method. Sam is an extreme example from this group as she rarely manages to implement her chosen strategy (condoms).

Sam is a 28 -year-old single woman living with family. She works and studies.

Louise: So tell me about the first time you used the morning after pill.

Sam: $\quad$ The guy I'd been seeing a couple of times, and ah, we just ended up having sex and the next day, like I didn't worry about contraception which was stupid, um. I just kept on telling myself 'It's alright I'll get the morning after pill'.... //

Louise: And why do you think you didn't use contraception? You said because you thought could use the morning after pill, did that go through your mind?

Sam: Yeah, and um, contraception doesn't. Well it enters my mind briefly and then flits right out, and that's probably a lot to do with self-respect and value and stuff. Boy how that can change! Like I've always been, like until recently I've always been scared of being rejected and I've always felt that it was my job to please a man, never the other way around. So the word 'no' rarely comes out of my mouth.

Louise: So asking for a condom is a bit much?

Sam: $\quad$ Yeah difficult. //

Sam: $\quad$ But um, last time, there was just no discussion of it, so that was it.

Louise: No discussion of contraception when you had sex?

Sam: Nup.

Louise: So you just went a long with it? Were you thinking 'Oh I'll just get the morning after pill'?

Sam: $\quad$ In a way yeah I think I did. I wasn't thinking very much. 


\section{ARTICLE}

Jane had had several incidents of missed pills and did not regard this as a problem. She intended to continue using the pill in this way, and was comfortable using EC as a backup when she needed to. She was concerned, however, about the assumptions made by her provider about her sexual relationship.

Jane is 27 years old, works full time, owns her own home and has been in a relationship for 1 year.

Louise: And how was the clinic when you got there?

Jane: $\quad$ Oh, it was alright, I didn't have to wait very long, and um, yeah it was fine, it was. It was funny, because they assume you've had a onenight stand ... They just go, 'Do you want to be tested for STDS [sexually transmitted diseases]?'. I'm like, 'No, no, this is my boyfriend, I've known him for four years, I've been going out with him for a year, I don't think you need to test for STDs'. They just assume that, you go, 'That's not what I'm in here for'. They don't ask, but they also just assume that that's what you're in for. Because I've never had a one-night stand with someone I don't know, I find that really, like 'No, no, don't get that impression'. You know, 'That's not what I've been doing'.

\section{Caught short}

The final group of five women all described their need for EC in terms of a sexual experience rather than their contraceptive choices. I have called this group of women 'caught short' as they describe an unplanned sexual experience in which they did not manage to implement their chosen contraceptive strategy. This group included women who preferred a high level of control over their contraception and those more comfortable with risk. For some it was their first sexual experience and for all of them it was the first time they had sex with a particular person. This experience was dominated by ideas of romance and feeling, much more so than for women having sex in a relationship. For these women a contraceptive strategy had not yet been devised or, if one had been, it was not effectively executed. Each woman describes the experience as unexpected and themselves as under-prepared. These women ranged in age from 19 to 46 years. Nicole discusses her experience of having sex for the first time.

Nicole is a 19-year-old student living at college. She had just ended a 2-month relationship at the time of the interview.

Louise: So tell me about that [needing the morning after pill], what happened?

Nicole: Well, it was actually my nineteenth birthday, and we went out and then we came back to college, that's where we had sex, in my room. Um, it was actually my first time, and it was sort of really overwhelming, and then the next day I was absolutely petrified, because we didn't use a condom, and that just freaked me out. Then I went to the health centre. But it was definitely a very scary experience. II

Louise: So what did you think about contraception on the night?

Nicole: Um, well, I didn't really expect to sleep with him that night, at all, so I hadn't planned anything. Um, but yeah that's sort of why it was really awful the next day. I was thinking I was just so stupid, it was just the stupidest thing I've ever done. So next time, definitely plan a lot more.

Louise: And what did he say about contraception on the night?
Nicole: Um, nothing, I think it was because neither of us said anything, and then it got out of hand, not well planned at all. //

Louise: And did he ever mention it again? The chance that you could get pregnant?

Nicole: No, he never mentioned it. I just don't think it crossed his mind.

\section{Discussion}

$\mathrm{EC}$ has the potential to be a valuable resource for both women and providers in attempting to manage fertility, but several barriers have prevented this potential from being fully realised. The history of contraception reveals that no new contraceptive technology has been introduced without controversy, and the interplay of powerful lobby groups. ${ }^{19}$ However, EC has also been thwarted by the propagation of incorrect information and the persistence of myths both among women and providers.

The stories presented here not only reveal what was different about how these women used EC, but also what was common to their experiences. Women were actively weighing up the benefits and disadvantages of different methods of contraception for themselves. Some of the factors that played a role in women's decision making about contraception included: the nature of the relationship; the nature of the sexual experience; their beliefs; advice (correct or incorrect) from health practitioners, friends or other 'experts'; their own health and perception of what is good or bad for their body; lifestyle implications of particular technologies; their own evaluation of the effectiveness of different contraceptives; and side effects. While most women could identify strategies that they actively choose and strategies they actively avoid, they were also aware that the best contraceptive strategy in theory might not always work in practice. To choose not to use the most effective technology available was not necessarily due to a lack of knowledge, but a different prioritising of issues to that of health care providers. Further research is needed to explore the different value systems and decision-making processes adopted by the two groups (users and providers) to encourage better communication and co-operation in the shared desire to most effectively use the available technologies.

The findings from this study challenge the types of assumptions that are often made about the users of EC. Contrary to popular perception, 'controllers' and 'thwarted controllers' show a high level of responsibility in planning and managing their contraception, while 'risk takers' were only seen to be taking risks in that they found the occasional use of EC to be an acceptable part of their overall contraceptive strategy. It is not surprising that a woman starting a new relationship could find herself unprepared and 'caught short'.

The four categories of users outlined here may not be exhaustive, and another researcher may have defined them differently, but the important finding is that users adopt subtly different approaches to using EC and respond to the need in different ways. Depending on the type of user, their needs at the time of accessing EC may differ substantially depending on their relationship status, contraceptive knowledge, and on the way they use EC. Some women may benefit from a discussion about their contraceptive strategy as use of EC may represent a crisis in their fertility management, while others are unlikely to benefit from this discussion as their alternative options may be very limited. Women like Jane may be offended by the implication that they are at risk of STDs, while others may well be at risk of STDs and may benefit from some discussion about this. 
It is important to note that no woman recruited into this study had experienced rape or sexual coercion and that this is an important subgroup of EC users not covered by this study. They are likely to have a very specific set of needs.

As suggested by Ziebland, EC occupies an 'anomalous position in the family planning repertoire' 20 because, by making it readily available, we are admitting that preventive measures may not always be possible in sexual relationships. This study sheds light on some of the ways in which preventive measures fail to occur in sexual relationships and how women respond to this failure. I hope the data presented here provide evidence that EC is experienced by women as a crucial technology in the prevention of unplanned pregnancy, given the issues that they face in managing their fertility. It would be a step in the right direction if we could acknowledge the legitimacy of women's ways of making sense of, and decisions about, contraception. And it would be a significant advance if we could stop giving mixed messages about EC and stop viewing it as a somehow less legitimate preventive strategy.

\section{Acknowledgements}

This research was carried out under the supervision of Professor Allan Kellehear and Associate Professor Jeanne Daly in the School of Public Health at La Trobe University.

Statements on funding and competing interests

Funding. This research was supported by a scholarship from the National Health and Medical Research Council.

Competing interests. None identified.

References

1 Glasier A. Emergency contraception. Br Med Bull 2000; 56: 729-738.

2 Boonstra H. Emergency Contraception: The Need to Increase Public Awareness. New York, NY: The Alan Guttmacher Institute, 2002; 3-6.

3 Ellertson C, Shochet T, Blanchard K, Trussell J. Emergency contraception: a review of the programmatic and social science literature. Contraception 2000; 61: 145-186.
4 Delbanco SF, Mauldon J, Smith MD. Little knowledge and limited practice: emergency contraceptive pills, the public, and the obstetrician-gynecologist. Obstet Gynecol 1997; 89: 1006-1011.

5 Crosier A. Women's knowledge and awareness of emergency contraception. Br J Fam Plann 1996; 22: 87-90.

6 Smith AM, Rissel CE, Richters J, Grulich AE, de Visser RO. Sex in Australia: reproductive experiences and reproductive health among a representative sample of women. Aust N Z J Public Health 2003; 27: 204-209.

7 Richters J, Grulich AE, de Visser RO, Smith AM, Rissel CE. Sex in Australia: contraceptive practices among a representative sample of women. Aust N Z J Public Health 2003; 27: 210-216.

8 Ziebland S, Maxwell K, Greenhall E. 'It's a mega dose of hormones, isn't it?' Why women may be reluctant to use emergency contraception. Br J Fam Plann 1996; 22: 84-86.

9 Barrett G, Harper R. Health professionals' attitudes to the deregulation of emergency contraception (or the problem of female sexuality). Sociol Health Illn 2000; 22: 197-216.

10 Boonstra H. Emergency contraception: increasing public awareness. Issues Brief (Alan Guttmacher Inst) 2003; 2: 1-4.

11 Gordon AF, Owen P. Emergency contraception: change in knowledge of women attending for termination of pregnancy from 1984 to 1996. Br J Fam Plann 1999; 24: 121-122.

12 Gooder P. Knowledge of emergency contraception amongst men and women in the general population and women seeking an abortion. $\mathrm{Br}$ J Fam Plann 1996; 22: 81-84.

13 Pyett P. Postcoital contraception: who uses the 'morning after pill'? Aust N Z J Obstet Gynaecol 1996; 36: 347-350.

14 Evans JK, Holmes A, Browning M, Forster GE. Emergency hormonal contraception usage in genitourinary medicine clinic attenders. Genitourin Med 1996; 72: 217-219.

15 ni Riain A. Increasing the effectiveness of contraceptive usage in university students. Eur J Contracept Reprod Health Care 1998; 3: $124-128$.

16 Tyden T, Wetterholm M, Odlind V. Emergency contraception: the user profile. Adv Contracept 1998; 14: 171-178.

17 Harvey MS, Beckman LJ, Sherman C, Petitti D. Women's experience and satisfaction with emergency contraception. Fam Plann Perspect 1999; 31: 237-240

18 Huberman M, Miles M. Data management and analysis methods. In: Denzin NK, Lincoln YS (eds), Collecting and Interpreting Oualitative Materials. Thousand Oaks, CA: Sage Publications, 1998.

19 Siedlecky S, Wyndham D. Populate and Perish: Australian Women's Fight for Birth Control. Sydney, Australia: Allen \& Unwin, 1990.

20 Ziebland S. Emergency contraception: an anomalous position in the family planning repertoire? Soc Sci Med 1999; 49: 1409-1417.

\section{HOW TO REGISTER FOR ACCESS TO THE ELECTRONIC JOURNAL}

\section{Registration Process}

1. On connecting with the Faculty website (www.ffprhc.org.uk), click on the picture of the 'Journal' to access the electronic Journal.

2. Next, under Related Links, click on 'Faculty Membership Activation'.

3. In the appropriate boxes enter your Surname, E-mail Address, Country and Membership Number (M000, D000, etc - six digits). NB. These boxes are case-sensitive.

4. Next, select a User Name and Password.

5. Ignore the box marked 'Ingenta Select ID number - CID'.

6. Click on 'Enable Access'.

7. A confirmation e-mail will be sent to you.

\section{After Registration}

Once you have registered you can access the Journal as follows:

1. On connecting with the Faculty website (www.ffprhc.org.uk), click on the picture of the 'Journal' to access the electronic Journal.

2. Select the volume and issue number.

3. Select the article you wish to view.

4. Enter your user name and password. 